\title{
DIALECTOLOGIA BRASILEIRA: O ATLAS LINGÜÍSTICO DO BRASIL
}

\author{
Jacyra Andrade Mota \\ Suzana Alice Marcelino Cardoso
}

\begin{abstract}
RESUMO: O trabalho parte de uma breve caracterizaçăo dos estudos dialetais no Brasil, traçando o seu percurso e assinalando a natureza da dominância do enfoque dado em cada época, para, a seguir, apresentar o Projeto Allas Lingüistico do Brasil que se desenvolve sob a responsabilidade de um Comitê Nacional. São trazidas informaçōes de cunho histórico e apresentadas as linhas metodológicas seguidas, para concluir-se com um informe sobre o estágio atual do Projeto e a importância de sua realização.
\end{abstract}

PALAVRAS-CHAVE: Dialetologia; Geolingüistica; Português do Brasil; Atlas lingüistico.

\section{Introdução}

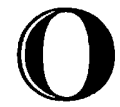

s estudos propriamente de Dialectologia brasileira se iniciam na primeira metade do século XIX, tendo como ponto de referência as considerações que o Visconde de Pedra Branca, Domingos Borges de Barros, escreve sobre o léxico do português do Brasil, publicadas na obra de Adrien Balbi, L'Atlas Ethnographique du Globe'.

\footnotetext{
Universidade Federal da Bahia.

' Cf. Cardoso, Suzana; Ferreira, C. , 1994, p. 37.
} 
MOTA, Jacyra A. e CARDOSO, Suzana Alice M. Dialectologia brasileira: o atlas lingüístico...

As observaçōes sobre o léxico constituem-se na primeira manifestaçāo mais amplamente documentada de reconhecimento da diversidade lingüistica em nosso pais, e, no caso inicial, atestada entre o falar de Portugal e o falar brasileiro. Tal linha de investigação prossegue por todo esse século. São glossários, léxicos, dicionários e vocabulários que vão tratar de assinalar as peculiaridades de áreas, caracterizando-as e distinguindo-as, e, ao mesmo tempo configurando a diversidade na considerada unidade do português brasileiro. Uma obra, não de caráter lexicográfico mas voltada, também, para o estudo do léxico, $O$ idioma hodierno de Portugal comparado com o do Brasil, publicada por José Jorge Paranhos da Silva, em 1879, se insere entre as demais, mas mantendo a tônica da intercomparação de fatos.

O conhecimento da variação geográfica de forma extensiva conduz a que se busquem formas de aprofundar o conhecimento de tais divergências a fim de melhor compreender usos e hábitos lingüisticos.

Movidos por esse novo enfoque, estudiosos se voltam para a análise intensiva e aprofundada de regiōes especificas, ocupando-se da produção de trabalhos monográficos que, sem deixar de caracterizar um ponto em relação a outro, buscam identificar, nos variados niveis, o que caracteriza o falar de uma região. Surgem, assim, monografias, que se constituem em marcos exemplares dos estudos nessa nova diretriz porque oferecem uma outra dimensāo aos estudos dialetais, ilustradas, consensualmente, pela sempre repetida trilogia dos trabalhos de áreas: $O$ dialeto caipira de Amadeu Amaral (1920), $O$ linguajar carioca em 1922 de Antenor Nascentes (1922) e $A$ lingua do Nordeste de Mário Marroquim (1934).

Partindo-se do especifico de ärea, aprofunda-se o particular a determinadas regiōes e retoma-se, em meados do século $\mathrm{XX}$, a idéia do global, com os estudos de geografia lingüistica que se concretizam com os atlas regionais e, mais recentemente, com o atlas lingüistico do Brasil no que se refere à lingua portuguesa. 


\section{Atlas lingüístico do Brasil: antecedentes}

A primeira manifestação em favor da elaboração de um atlas lingüistico do Brasil remonta a 1952, quando, através do Decreto 30 . 643 , de 20 de março, assentava-se, no seu Art $3^{\circ}$, como principal finalidade da Comissāo de Filologia da Casa de Rui Barbosa a "elaboração do atlas lingüistico do Brasil". Tal determinação foi regulamentada pela Portaria n. ${ }^{\circ} 536$, de 26 de maio do mesmo ano, a qual, ao baixar instruçōes referentes à execuçāo do decreto de criação do Centro de Pesquisas Casa de Rui Barbosa, estabeleceu como finalidade principal, entre as pesquisas a serem planejadas, a própria elaboraçāo do atlas lingüistico do Brasil.

Nascida a idéia, ganha ela corpo nas proposiçōes de Serafim da Silva Neto, Celso Cunha e Antenor Nascentes. Os dois primeiros, por ocasião do III Colóquio Internacional de Estudos Luso-Brasileiros, realizado em Lisboa em 1957, defendem a necessidade de elaboraçāo de atlas lingüisticos regionais, com argumentos bastante sólidos e convincentes. A esses dois filólogos soma-se Antenor Nascentes que, assumindo a mesma posiçāo, dá passos iniciais concretos com a publicação das Bases para a elaboraçāo do atlas lingüistico do Brasil (1958. 1961), obra em dois volumes, na qual fornece diretrizes gerais para a escolha de localidades, de informantes e para a elaboração do questionário lingüistico, e propōe, muito claramente, a elaboração de atlas regionais.

Retoma-se no atual Projeto a idêia de realização do atlas lingüistico do Brasil e defende-se uma politica de integração e coordenação do trabalho que se vem desenvolvendo, com a realização de atlas regionais, com vistas a se alcançar o objetivo final da produção de um atlas nacional.

Em 1952, quando se explicitou pela primeira vez o desejo de elaboraçāo de um atlas lingüístico brasileiro, momento em que a Europa já havia produzido alguns atlas - como o Atlas Linguistique de la France (1902-1912), Linguistischer Atlas des Dakorumänischen Sprachgebietes (1912), Atlas Linguistique de la Corse (1923-1939), Deutscher Sprachatlas (1926), Sprach und Sachatlas Italiens und der Südschweiz 
MOTA, Jacyra A. e CARDOSO, Suzana Alice M. Dialectologia brasileira: o atlas lingüistico...

(1928-1940) só para citar atlas da primeira metade deste século - e a Peninsula Ibérica, em particular, tentava concluir o Atlas Lingüistico da Peninsula lbérica, iniciado em 1925, as condiçōes do Brasil, obviamente, eram bem diversas das que hoje se nos apresentam. A população, segundo o censo de $1950^{2}$, atingia a cifra de 51944397 habitantes, dos quais 33161506 se situavam nas zonas rurais e apenas 18782 891 estavam estabelecidos nas zonas urbanas, ou seja, aproximadamente $63 \%$ da população se encontrava no campo e apenas $37 \%$ nas grandes cidades, o que revela a maior concentração demográfica fora dos centros urbanos. Os meios de comunicação - rádio, televisāo, telefone - tinham um perfil muito tímido cujos dados não vêm registrados nas estatisticas para esse ano. A extensāo da rede de estradas de ferro em tráfego alcançava $36681 \mathrm{~km}$. As rodovias se estendiam por $341035 \mathrm{~km}$. As empresas aéreas civis atingiam um percurso de $96600775^{3} \mathrm{~km}$ e a navegação maritima e a fluvial apresentavam um movimento de 406 embarcaçōes em tráfego. Decorridos quase cinqüenta anos, a situação que apresenta, hoje, o pais no tocante a esses mesmos itens, é - como não poderia deixar de sê-lo - bem diferente. Conta-se com os seguintes números segundo os dados do censo de 1991 de referência aos itens citados: população geral de 146 917459 habitantes dos quais 110875826 se situam na zona urbana e 36041633 na área rural, o que revela uma total inversão dos números se comparados aos registrados para 1950; a rede telefônica, que nem chega a ser levantada nas estatisticas disponiveis de 1950, apresenta, para 1991, um total de 15922 localidades atendidas com 14426673 telefones instalados; a rede ferroviária conta com $30282 \mathrm{~km}$ - caso único de modificação para menos com uma reduçāo de cerca de 6000 $\mathrm{km}$ em relaçāo a 1950, fato deplorável, para não dizer criminoso, em relação ao sistema de transporte do paîs; o tráfego aéreo atinge

2 Os dados estatisticos referidos foram extraidos do Anuário Estatistico do Brasil - 1954. Ano XV. Rio de Janeiro, IBGE-Conselho Nacional de Estatistica, 1954 e do Anuário Estatístico do Brasil - 1993. Rio de Janeiro, Fundação Instituto Brasileiro de Geografia e Estatistica-IBGE, 1993.

3 Os dados relativos à aeronáutica ctvil referem-se ao ano de 1952. 
$287761775 \mathrm{~km}$; e a navegação conta com um movimento total de 46310 embarcaçōes.

Esse breve perfil de realidades - a do passado e a atual - conduz a algumas consideraçōes que são, de certo modo, evidentes.

Os limites geográficos tornaram-se tênues, e mais tênues, ainda, se pensarmos na invasão domiciliar de informações universais e simultâneas aos acontecimentos que facultam o rádio, a televisão e a informática; na mobilidade social, seja por obrigaçāo de trabalho, seja pelo lazer, que faz de cada rincāo uma miniatura do universo e de cada cidadão cada vez mais um homem sem fronteiras; na politica econômica de fomento ao turismo - fonte moderna de captação de recursos explorada por ricos e pobres - que põe em contacto diuturnamente populaçōes extremas, costumes dispares, usos linguageiros diferenciados; nos avanços tecnológicos que encurtam as distâncias e aproximam os povos. O mundo moderno transforma-se num grande coletivo; é o momento da globalização.

Tais constataçōes levam, inexoravelmente, à afirmação categórica e óbvia: o mundo mudou, o Brasil mudou muito nesses últimos cinqüenta anos. A mudança da configuração demográfica do país com o aumento de concentração da população nos grandes centros urbanos, com o esvaziamento das áreas rurais e com a intensa migração interna tem trazido não só uma nova dimensāo social mas também politica que, por certo, se fazem acompanhar de mudanças lingüisticas cuja extensão ainda não podemos avaliar. Em decorrência, a lingua sofre, também, mutações consideráveis e ágeis. Tudo isso se constitui razão maior para reafirmar a necessidade de descrever-se a realidade brasileira antes que se percam traços e usos, formas e estruturas ainda nāo formalmente identificadas, registradas e catalogadas, como bem chamou a atençāo Boléo (1976:342) ao afirmar, de referência à demora na concretizaçāo do atlas lingüistico de Portugal:

Quand nous, Portugais, nous nous déciderons à èlaborer notre atlas linguistique, nous arriverons dejjà trop tard car de nombreux termes, expressions et coutumes auront disparu, emportant avec eux la clé d'un gran nombre de problèmes. 
MOTA, Jacyra A. e CARDOSO, Suzana Alice M. Dialectologia brasileira: o atlas lingüistico...

De outra parte, as dificuldades apontadas para a concretizaçāo da pesquisa lingüistica, mais especificamente a dialetal, no Brasil, parecem de certo modo obviadas. A ausência de vias de comunicação, unindo os diferentes e mais longinquos pontos do pais, bem como o "desinteresse por parte do elemento masculino", mencionado por Nascentes (1958:7), nāo se constituem, hoje, em óbice. A rede de estradas tem crescido e melhorado, gradativamente, de condiçōes e não são mais as mãos femininas, majoritariamente como outrora, que lavram o terreno da dialectologia.

Sem desconhecer-se a importância de outros ramos dos estudos lingüisticos e sem querer minimizar-se o papel de cada um deles, nesse momento da história, é urgente que se enfrente a descriçāo da realidade lingüistica brasileira no seu plano geográfico e o melhor caminho, para esse conhecimento de amplitude continental, parece ser o que propōe a Dialectologia, concebida nāo como um ramo dos estudos lingüisticos voltado exclusivamente para as questões diatópicas, mas partindo-se do principio, como bem assinalou Lope Blanch (1978: 53-4), de que

La dialectologia puede, evidentemente, beneficiarse mucho con las aportaciones de la sociolingüistica, como de hecho ya se há estado beneficiando. $\mathrm{El}$ progreso metodológico que há establecido la sociolingüistica con su rigurosa y detenida consideración de factores sociológicos antes sólo superficialmente atendidos por la dialectologia, es aportación de primera magnitud, que la actividad dialectológica habrá de tener ahora muy en consideración (grifo nosso).

\section{Atlas lingüístico do Brasil: o projeto em curso}

\subsection{Implantação do Projeto}

Retomando a idéia de um atlas lingüistico do Brasil, lançada em 1952, pesquisadores da área de Dialectologia reúnem-se em Sal- 
vador, Bahia, em novembro de 1996, no Seminário Caminhos e Perspectivas para a Geolingüistica no Brasil e assumem esse desafio. Nesses três dias de discussāo em que foram abordadas temáticas referentes a uma politica geolingüistica para o Brasil e a questōes metodológicas em geral, ficou também acertada a criação de um Comitê Nacional que, a partir daquele momento, se encarregaria de dar curso às decisões do encontro e implementar o projeto nacional para execução do atlas lingüistico do Brasil, constituido com representantes de cada um dos atlas publicados e com um representante dos atlas em curso. Integram, assim, o Comitê, sob a presidência de Suzana Cardoso (Universidade Federal da Bahia): Jacyra Mota (Universidade Federal da Bahia), Maria do Socorro Aragão (Universidade Federal da Paraiba/Universidade Federal do Ceará), Mário Zágari (Universidade Federal de Juiz de Fora), Vanderci Aguilera (Universidade Estadual de Londrina) e Walter Koch (Universidade Federal do Rio Grande do Sul).

Com esse Projeto dá-se curso ao desejo de realizaçāo do atlas lingüistico nacional e defende-se uma política de integração e coordenação do trabalho no campo da Geolingüistica com vistas a se alcançar o objetivo final da produção de um atlas geral do Brasil.

O quadro histórico-social do país, hoje, e a necessidade do conhecimento sistemático e geral da realidade lingüistica brasileira, necessário sobremodo à difusão de um ensino adequado ao carăter pluricultural do Brasil, estão a exigir, sem mais demora, um esforço coletivo na tentativa de se desenvolverem estudos mais amplos que levem a esse conhecimento global que se afigura tarefa da Dialectologia brasileira, nesse finnal de milènio, a se concretizar, fundamentalmente, com a realização do atlas lingüistico geral do Brasil.

Situações, fatos e dados lingüisticos e extralingüisticos justificam a deliberação de fazer-se um atlas lingüístico. O percurso histórico dos estudos sobre o português estāo a cobrar esse passo. E, tudo indica, parece ter chegado a hora. Razōes de ordem lingüistica stricto sensu, de ordem social, de ordem histórica, e ainda relacionadas à 
MOTA, Jacyra A. e CARDOSO, Suzana Alice M. Dialectologia brasileira: o atlas lingüistico...

politica de ensino da lingua materna e à própria política de entendimento da diversidade de usos do português parecem, de forma resumida, constituirem-se na justificativa do que se propõe.

Em se tratando do nosso pais, a inexistência de dados que apontem, de maneira ampla e geral, as caracteristicas do português no território nacional apresenta-se como primeira razão. Os estudos dialetais que se iniciaram no século passado, voltados principalmente para a identificação das diferenças lexicais, e as abordagens da primeira metade deste século, com estudos de natureza monográfica e recobrindo toda uma área, têm funcionado como sondagens iniciais, exploraçōes prévias que esboçam caracteristicas e denotam traços particulares de áreas e regiōes.

O quadro atual demonstra que há uma preocupação, de certo modo nacional, com a geografia lingüistica no Brasil e afigura-se como o prenúncio da vontade ainda não formalmente manifesta, talvez, mas sentida, por certo, de que é urgente uma descriçāo acurada da realidade lingüistica brasileira para que se alcance o pleno conhecimento do português do Brasil.

Se por um lado já se dispōe de estudos preliminares, passiveis de instrumentar um trabalho maior, por outro, ainda se padece da ausência de dados lingüisticos que permitam traçar uma divisāo dialetal do Brasil apesar de contar-se com a divisāo proposta por Nascentes (1953), fundamentada na realização das médias pretônicas e na entoação.

Um segundo fator está a apontar para a necessidade de um atlas do Brasil. É preciso ter-se a multidimensionalidade da lingua no pais não apenas para efeito de precisar e demarcar espaços geolingüisticos, mas para que se possa também contribuir de forma direta para um melhor equacionamento entre a realidade de cada área $\mathrm{e}$ o ensino da lingua materna que nela se processa.

A implantaçāo e desenvolvimento do Projeto se constituirá em substancial contribuição para o entendimento da lingua e de suas variantes, eliminando visōes distorcidas que privilegiam uma varian- 
te tida como culta e estigmatizam as demais variantes, causando, assim, ao ensino-aprendizagem da lingua materna consideráveis prejuízos.

Em resumo, o conhecimento sistemático da variaçāo, a delimitação de áreas lingüisticas específicas e a relaçāo entre os diferenciados usos que se faz da lingua constituem-se num beneficio de cunho social.

Admitindo-se ter chegado a hora do atlas lingüístico do Brasil, como de fato se reconhece, uma preliminar se faz necessário assentar: os atlas regionais, publicados, em curso ou no desiderato de grupos de pesquisa, nāo interferem na proposta de elaboração de um atlas geral do Brasil. Ao contrário, servem de apoio e devem continuar a ser executados porque têm por finalidade um conhecimento mais detalhado e circunstanciado de cada região.

\subsection{Objetivos}

Os objetivos do Projeto Atlas Lingüistico do Brasil podem ser, assim, resumidamente definidos:

1. Descrever a realidade lingüística do Brasil, no que tange à lingua portuguesa, com enfoque prioritário na identificaçāo das diferenças diatópicas (fônicas, morfossintáticas, léxico-semânticas e prosódicas) consideradas na perspectiva da Geolingüistica.

2. Oferecer aos estudiosos da lingua portuguesa (lingüistas, lexicólogos, etimólogos, filólogos, etc. ), aos pesquisadores de áreas afins (história, antropologia, sociologia, etc. ) e aos pedagogos (gramáticos, autores de livros-texto para o $1^{\circ} \mathrm{e}$ $2^{\circ}$ graus, professores) subsidios para o aprimoramento do ensino/aprendizagem e para uma melhor interpretação do caráter multidialetal do Brasil. 
MOTA, Jacyra A. e CARDOSO, Suzana Alice M. Dialectologia brasileira: o atlas lingüistico...

3. Estabelecer isoglossas com vistas a traçar a divisão dialetal do Brasil, tornando evidentes as diferenças regionais atravês de resultados cartografados em mapas lingüisticos e de estudos interpretativos de fenômenos considerados.

4. Examinar os dados coletados na perspectiva de sua interface com outros ramos do conhecimento - história, sociologia, antropologia, etc. - de modo a poder contribuir para fundamentar e definir posiçōes teóricas sobre a natureza da implantação e desenvolvimento da língua portuguesa no Brasil.

5. Oferecer aos interessados nos estudos lingüisticos um imenso volume de dados que permita aos lexicógrafos aprimorarem os dicionários, ampliando o campo de informaçōes; aos gramáticos atualizarem as informaçōes com base na realidade documentada pela pesquisa empirica; aos autores de livros didáticos adequarem a sua produção à realidade cultural de cada regiāo; aos professores aprofundar o conhecimento da realidade lingüistica, refletindo sobre as variantes de que se reveste a lingua portuguesa no Brasil e, conseqüentemente, encontrando meios de, sem desprestigiar os seus dialetos de origem, levar os estudantes ao dominio de uma variante tida como culta.

6. Contribuir para o entendimento da lingua portuguesa no Brasil como instrumento social de comunicaçāo diversificado, possuidor de várias normas de uso mas dotado de uma unidade sistêmica.

\subsection{Desenvolvimento do Projeto}

O desenvolvimento do Projeto está previsto em quatro etapas: a primeira compreende a fase inicial de implantação do Projeto com a fixaçāo dos critérios para a escolha das localidades, a definição do perfil dos informantes e a preparação dos questionários lingüisticos; a segunda etapa é voltada especialmente para a preparaçāo dos in- 
quiridores e a constituição do corpus; uma terceira etapa destina-se à transcriçāo e análise dos dados recolhidos, à elaboraçāo de cartas lingüisticas e comentários; a etapa final é a de editoraçāo e publicação dos resultados.

\subsection{Aspectos metodológicos}

A metodologia a ser utilizada na elaboração do Atlas Lingüistico do Brasil tem sido discutida desde a sua implantação em 1996 , em reuniōes do Comitê Nacional, em discussões com especialistas brasileiros e de universidades estrangeiras, em diversas oportunidades, especialmente em congressos nacionais e internacionais.

Entre os pesquisadores estrangeiros com os quais o Comitê Nacional tem mantido contato, deve-se ressaltar o Professor Michel Contini, da Université Stendhal, Grenoble, um dos autores do Atlas Linguistique Roman (ALIR), que esteve também presente no Seminário Nacional "Caminhos e Perspectivas para a Geolingüistica no Brasil", em que se iniciou o projeto ALiB.

O Comitê Nacional realizou a sua primeira reunião em Maceió, na UFAL, nos dias 11 e 12 de março de 1997, seguindo-se uma segunda reunião em julho do mesmo ano, em Belo Horizonte, nos dias 13 e 14. A terceira reunião realizou-se nos dias 14 e 15 de julho de 1998, em Natal, a quarta em Florianópolis, na UFSC, em 27 de fevereiro de 1999 e a última, em Salvador, na UFBA, nos dias 06, 07, 09 e 10 de setembro de 1999 .

Para uma discussão mais ampla dos procedimentos metodológicos a serem adotados na pesquisa de campo, realizou-se, na UFBA, de 06 a 10 de setembro de 1999 um "Workshop sobre técnicas e métodos de trabalho de campo para a preparação de inquiridores para o Atlas Lingüistico do Brasil", que contou com a participação de cinco dos seis membros do Comitê Nacional, professores e estudantes de doze Estados e quinze universidades brasileiras. Um outro evento da 
MOTA, Jacyra A. e CARDOSO, Suzana Alice M. Dialectologia brasileira: o atlas lingüistico...

mesma natureza está previsto para realizar-se em março de 2000 , no Paraná, sob o patrocinio da Universidade Estadual de Londrina.

\subsubsection{Rede de pontos}

No que se refere à rede de pontos, foram selecionadas 235 localidades, restando quinze pontos a serem posteriormente definidos em funçāo do que as observaçōes in loco venham a sugerir e justificar, de modo a que se alcance o número máximo de 250 pontos.

Quanto às localidades escolhidas, além da distribuição espacial, consideram-se os critérios: (a) a existência de zonas dialetais já delimitadas através de pesquisas anteriores - como, por exemplo, a área do 'falar baiano'4, compreendida por Bahia, Sergipe e parte setentrional de Minas Gerais; os falares 'baiano', mineiro' e 'paulista'5; em Minas Gerais; a delimitação de áreas dialetais, baseada nos dados do Atlas Lingüistico do Paraná e do Atlas lingüístico e etnográfico da regiāo sul, em andamento; (b) a importância da localidade no Estado ou regiāo, incluindo-se, por exemplo, as capitais de Estado e cidades de grande e médio porte, lingüisticamente representativas. Entre as capitais excluem-se apenas o Distrito Federal - em vista da data de sua criação e, em conseqüência, do fato de ter população proveniente ou descendente de diversos pontos do país - e Palmas, capital do Tocantins, cidade ainda em formaçāo, sem habitantes nela nascidos; (c) os limites interestaduais e internacionais.

$\mathrm{Na}$ escolha das localidades foi também avaliada a proposta de Nascentes em Bases para a elaboração do atlas lingüistico do Brasil', tendo-se chegado a cento e trinta e quatro localidades coincidentes com os seiscentos e seis pontos por ele sugeridos em 1958.

\footnotetext{
4 O 'falar balano' na proposta de Nascentes (1953: 25-26) compreenderia também o oeste de Goiảs, área sobre a qual ainda nāo dispomos de dados.

5 Cf. Zágari. Mário. Os falares mineiros: Esboço de um Atlas Lingüistico de Minas Gerais. In Agullera, Vanderci (1998:31-54).

B Cf. Nascentes, Antenor, 1958, p. 19-22.
} 
Com relação aos atlas regionais jả publicados ${ }^{7}$ registram-se trinta e sete casos de coincidência - nove do Atlas Prévio dos Falares Baianos (APFB), dois do Atlas Lingüistico de Sergipe (ALS), dezessete do Esboço de um Atlas Lingüístico de Minas Gerais (EALMG), três do Atlas Lingüistico da Paraiba (ALPB) e seis do Atlas Lingüistico do Paraná (ALPR).

O quadro em anexo fornece uma visão global da distribuição da rede de localidades pelas regiōes e Estados brasileiros.

\subsubsection{Informantes}

Quanto aos informantes, ficou fixado o número de quatro por localidade - exceto nas capitais de Estado, onde serāo inquiridos oito informantes -, distribuidos eqüitativamente por duas faixas etárias de 18 a 30 anos e de 45 a 60 anos - e contemplando os dois gêneros. Nas capitais, levam-se em conta também as diferenças quanto à escolaridade, admitindo-se quatro informantes de nivel universitário e quatro que - como nas demais localidades - tenham cursado até a quarta série do primeiro grau.

A relação do informante com o ambiente sociocultural em que vive deve ser controlada através da ficha a ser preenchida, onde constam indagações sobre profissāo (inclusive dos pais e cônjuge), renda individual e familiar, contato com os meios de comunicação (TV, rádio, jornal, revista), diversões preferidas e participação em atividades religiosas.

7 Com as localidades do APFB coincidem: Barra. Caititè. Carinhanha, Itaberaba. Jacobina, Jeremoabo, Santa Cruz de Cabrälia, Santana e Vitória da Conquista; com as do ALS: Estância e Propriá; com as do ALPB: Cajazeiras, Campina Grande, Joāo Pessoa e Patos: com as do EALMG: Belo Horizonte, Caratinga. Diamantina. Formiga, Itajubá, Januária. Juiz de Fora, Montes Claros. Ouro Preto. Passos, Patos de Minas, Pirapora. São Joāo del Rei, Uberlândia, Unai, Varginha e Viçosa: com as do ALPR: Adrianópolis, Barracão. Curitiba. Guarapuava, Lapa e Umuarama. 
MOTA, Jacyra A. e CARDOSO, Suzana Alice M. Dialectologia brasileira: o atlas lingüistico...

Como é a norma em trabalhos desse tipo, os 1104 informantes devem ser naturais da região lingüistica pesquisada, da qual nāo se tenham afastado por mais de 1/3 de suas vidas, controlando-se rigorosamente os afastamentos e tempos de permanência fora da localidade.

Os informantes devem ter uma profissāo definida, que não requeira grande mobilidade e que se encontre inserida no contexto social local. Por fim, alëm da condiçāo primeira de terem nascido na localidade em questão, os informantes devem, preferentemente, ser filhos de pais da região lingüistica em estudo.

\subsubsection{Questionários}

De referência ao questionário lingüistico, deliberou-se pela aplicação de quatro tipos de questionário direcionados, especificamente, cada um deles para os aspectos semântico-lexical, fonético-fonológico, morfossintático e prosódico, além de questōes referentes à pragmática e sugestões de temas para o registro de discursos semi-dirigidos. Na sua elaboração foram considerados estudos de diferente natureza existentes sobre o português regional do Brasil, os questionários dos atlas já publicados e aqueles disponiveis dos atlas em andamento, e também os questionários do ALiR-Atlas Linguistique Roman e do Atlas Lingüistico-Etnográfico de Portugal e da Galiza. Foram, ainda, examinados os resultados cartografados nos atlas regionais.

Uma primeira versão dos Questionários foi publicada pela Universidade Estadual de Londrina e vem sendo testada em inquéritos experimentais, devendo ser reformulada, em função dos primeiros resultados e das discussões com diversos pesquisadores.

\section{Considerações finais}

Considerando-se o percurso da Dialectologia brasileira até os dias de hoje, constata-se que este ramo de estudos lingüisticos alcançou já uma fase bastante produtiva, tanto em relação aos levanta- 
mentos sistemáticos de dados empíricos de que resultaram cinco atlas regionais publicados, vârios em fase de elaboração - alguns já em vias de publicação - e inúmeros trabalhos de cunho monográfico, especialmente teses de doutorado e dissertaçōes de mestrado, quanto à inclusão de novos parâmetros a serem pesquisados, ao lado do diatópico, estreitando-se os vínculos com a Sociolingüística. Este contexto apresenta-se como altamente favorável à realização de um atlas lingüistico de cunho nacional e voltado para a lingua portuguesa, que reflita os aspectos mais significativos da variação do português no Brasil, abarcando todas as áreas brasileiras e inserindo o pais entre aqueles que, neste fim de século, já possuem os seus Atlas nacionais

RÉSUMÉ: Partant d'une brève carcatérisation des études dialectales au Brésil, ce travail trace son parcours en signalant la nature de la prédominance de l'approche adoptée à chaque époque pour présenter ensuite le Projet de l'Atlas Linguistique du Brésil, qui se développe sous la responsabilité d'un Comité National. Des informations de type historique sont présentées, ainsi que les lignes méthodologiques du Projet $e$ on conclut en exposant l'état actuel et l'importance de sa réalisation pour la connaissance du portugais brésilien.

MOTS CLÉS: Dialectologie; Géolinguistique; Portugais brésilien; Atlas linguistique.

\section{Bibliografia}

AGUILERA, V. (1994) Atlas Lingüistico do Paraná. Curitiba: Imprensa Oficial do Estado.

ARAGĀO, M. do S. e MENEZES, C. B. de (1984) Atlas lingüistico da Paraíba. I-II. Brasilia: Universidade Federal da Paraiba: CNPq.

BLANCH, M. L. La sociolingüistica y la dialectologia hispánica. In: ALVAR, M. \& BLANCH, M. L. (1978) En torno a la sociolingüistica. México: UNAM, p. 33-58. 
MOTA, Jacyra A. e CARDOSO, Suzana Alice M. Dialectologia brasileira: o atlas Lingüistico...

BOLÉO, M. de Paiva. (1975-1976) Le matériel de LI. L. B. et quelques ètudes de comparaison avec l'Atlas Lingũistico de la Peninsula Ibérica' et l' 'Atlas Prévio dos Falares Baianos'. Revista Portuguesa de Filologia, v. XVII, tomos I e II, Coimbra.

CARDOSO, S.; FERREIRA, C. (1994) A Dialetologia no Brasil. São Paulo: Contexto.

COMITÊ NACIONAL DO PROJETO ALiB. (1998) Allas Lingüístico do Brasil Questionários. Londrina: Ed. UEL.

FERREIRA, C.; MOTA, J.; FREITAS, J.; CARDOSO, S.; ANDRADE, N.; ROLLEMBERG, V.; ROSSI, N. (1987) Atlas lingüistico de Sergipe. Salvador: UFBA-FUNDESC.

MARROQUIM, M. (1996) A lingua do Nordeste: Alagoas e Pemambuco. $3^{*}$ ed. Curitiba: HDLivros.

NASCENTES, A. (1953) O linguajar carioca. Rio de Janeiro: Simōes.

. (1961) Bases para a elaboraçāo do atlas lingüístico do Brasil. Rio de Janeiro: MEC, Casa de Rui Barbosa, vol. I, 1958, vol. II.

RIBEIRO, J.; ZẢGARI, M. et al. (1977) Esboço de um Atlas Lingüistico de Minas Gerais, I. Rio de Janeiro: Fundação Casa de Rui Barbosa: Universidade Federal de Juiz de Fora.

ROSSI, N., FERREIRA, C. e ISENSEE, D. (1963) Atlas Prévio dos Falares Baianos. Rio de Janeiro: INL-MEC.

ZÁGARI, M. R. Os falares mineiros. In AGUILERA, Vanderci. (Org.) (1998) A geolingüistica no Brasil. Caminhos e perspectivas. Londrina: Ed. UEL. p. 34-35. 
Rev. ANPOLL, n. 8, p. 41-57, jan./jun. 2000

\section{ANEXO}

\section{Quadro - Localidades selecionadas para o 'Atlas Linguiistico do} Brasil'

\begin{tabular}{|c|c|c|c|}
\hline Região & Estado & $\begin{array}{c}\mathrm{N}_{0^{\circ}} \\
\text { pontos }\end{array}$ & $\begin{array}{l}\text { Totais } \mathrm{p} / \\
\text { região }\end{array}$ \\
\hline \multirow{8}{*}{ NORTE } & Pará & 09 & \\
\hline & Amazonas & 05 & \\
\hline & Amapá & 02 & \\
\hline & Acre & 02 & \\
\hline & Rondônia & 02 & \\
\hline & Tocantins & 02 & \\
\hline & Roraima & 01 & \\
\hline & & & 23 \\
\hline \multirow{10}{*}{ NORDESTE } & Bahia & 21 & \\
\hline & Ceará & 11 & \\
\hline & Pernambuco & 11 & \\
\hline & Maranhão & 08 & \\
\hline & Paraíba & 05 & \\
\hline & Alagoas & 04 & \\
\hline & Rio Grande do Norte & 04 & \\
\hline & Piauí & 04 & \\
\hline & Sergipe & 03 & \\
\hline & & & 71 \\
\hline \multirow{4}{*}{ CENTRO-OESTE } & Goiás & 09 & \\
\hline & Mato Grosso & 07 & \\
\hline & Mato Grosso do Sul & 05 & \\
\hline & & & 21 \\
\hline \multirow{5}{*}{ S UDESTE } & São Paulo & 39 & \\
\hline & Minas Gerais & 22 & \\
\hline & Rio de Janeiro & 13 & \\
\hline & Espírito Santo & 05 & \\
\hline & & & 79 \\
\hline \multirow{4}{*}{ S UL } & Rio Grande do Sul & 16 & \\
\hline & Paraná & 16 & \\
\hline & Santa Catarina & 09 & \\
\hline & 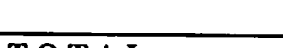 & & 41 \\
\hline
\end{tabular}

